\title{
El ritual de la lealtad: el recibimiento del real sello en Guatemala (1793)
}

\author{
The ritual of loyalty: the reception of the royal seal in Guatemala (1793)
}

Alexánder Sánchez Mora

Escuela de Filología, Lingüística y Literatura, Universidad de Costa Rica, Costa Rica

*Autor a quien se dirige la correspondencia: alexander.sanchez@ucr.ac.cr

Recibido: 11 de mayo de 2021 / Aceptado: 8 de octubre de 2021

Resumen

- 1 recibimiento del real sello fue uno de los más destacados ceremoniales de exaltación de la lealtad en las - audiencias americanas. La Breve relación de la solemnidad y augusta pompa con que se recibio en la Capital del Reyno de Guatemala el Real sello de nuestro reinante Catolico Monarca el Señor Carlos IV (1793) es la única de este tipo que se publicó en el reino de Guatemala. Este artículo pretende dar cuenta, a partir del estudio de su estructura retórica o dispositio, de la persistencia de un modelo de escritura festiva — patrones estéticos y políticos - que comienza a desarrollarse en el siglo XVI, pero que a fines del XVIII muestra claros signos de transformación. Además de destacarse el aporte del real sello a la construcción simbólica del poder real, se busca demostrar la superposición de las fórmulas retóricas barrocas e ilustradas en el periodo final de la colonia.

Palabras clave: Relaciones de fiestas, real sello, literatura colonial, reino de Guatemala, Carlos IV

\section{Abstract}

The reception of the royal seal was one of the most outstanding ceremonies of exaltation of loyalty in Royal 1 courts in all America. Breve relación de la solemnidad y augusta pompa con que se recibio en la Capital del Reyno de Guatemala el Real sello de nuestro reinante Catolico Monarca el Señor Carlos IV (1793) shows the persistence of a festive writing model - aesthetic and political patterns- - which began to develop in the $16^{\text {th }}$ century, but which at the end of the $18^{\text {th }}$ century shows clear signs of transformation. In addition to highlighting the contribution of the royal seal to the symbolic construction of royal power, it seeks to demonstrate the superposition of baroque and illustrated rhetorical formulas in the final period of the colony.

Keywords: Baroque festivals, royal seal, colonial literature, Kingdom of Guatemala, Charles IV 


\section{El real sello: instrumento y símbolo del poder ${ }^{1}$}

E n la sociedad del Antiguo Régimen, las festividades enfocadas en la exaltación de la lealtad hacia el sistema político, encarnado por la casa dinástica reinante, ocuparon un sitial de honor. La composición de los actos festivos se dirigía a fomentar sentimientos de afinidad e identificación hacia las personas, instituciones y símbolos de la monarquía hispánica, de modo tal que esto contribuyera a asegurar su proyección futura. Así considerada, la fiesta barroca puede ser vista como un ritual de sumisión en el que las artes se ponen al servicio de una empresa deslumbramiento que envuelve a los espectadores (Vincent, 1996, p. 157).

Este concepto de sumisión ante la autoridad del príncipe comporta una participación jerarquizada, como protagonistas o espectadores, dentro de roles claramente asignados de conformidad con un discurso ritual. La estricta reglamentación del puesto que los sujetos transindividuales, entendidos como colectivos sociales y corporativos, ocupan en el fasto es una proyección simbólica de la estructura social y del estado. Se trata de celebraciones que en forma periódica cantan las glorias de la monarquía y que junto a los rituales de legitimidad dinástica y pacto con el reino incluyen otros relacionados con la trayectoria vital de los miembros de la realeza (García Bernal, 2006, p. 231).

Dentro de las celebraciones de la lealtad, es posible ubicar las relacionadas con eventos de la vida de los miembros de la familia real (nacimientos, cumpleaños, bodas) y otras de un carácter marcadamente institucional, como las juras y proclamaciones, los recibimientos del real sello y los recibimientos de autoridades, en especial los reyes y virreyes.

El real sello constituyó una de las insignias más destacadas de la soberanía del monarca. En un plano simbólico, representaba la justicia que dimanaba del rey hacia sus súbditos como garantía de convivencia pacífica y de respeto a los derechos y méritos de cada quien. En la administración de justicia, constituía un instrumento de validación y reconocimiento de los documentos que se expedían en nombre del rey (Sanz García-Muñoz, 2014, p. 50). Esta doble condición consta desde su origen en las chancillerías castellanas,

1 Este artículo forma parte de la investigación doctoral que culminó en la la tesis titulada "Literatura y fiesta en las márgenes del imperio: las relaciones de fiestas en Centroamérica, s. XVII a XIX", defendida en la Universidad de Sevilla (Sánchez Mora, 2015). pero gozará de un particular desarrollo cuando sea trasladado a los territorios españoles en el continente americano.

Aunque los rituales de celebración de la lealtad en los virreinatos americanos han sido ampliamente estudiados, no sucede lo mismo con los fastos dedicados al real sello. La labor más destacada en torno a su investigación corresponde a la efectuada por Gómez Gómez (2007, 2008, 2009, 2014, 2015, 2021), a la que se ha sumado la de su discípulo Ramírez Barrios (2020) sobre Perú. También es necesario destacar las contribuciones de Valenzuela Márquez (1999) sobre Chile, Sanz García-Muñoz (2014) sobre Panamá y, para el caso en particular de nuestro interés, García Bernal (2014) sobre Guatemala.

\section{El recibimiento del real sello en Guatemala}

En las Indias, la primera persona que obtuvo la autorización para emplear el real sello fue el propio Cristóbal Colón en 1493, cuando se preparaba para su segundo viaje (Gómez Gómez, 2014, p. 20). El primer recibimiento del real sello data de 1531 en Nueva España, su uso obligatorio para la administración indiana se incluyó en las Leyes Nuevas de 1542 y el ritual de recepción fue fijado en la Recopilación de 1680 (Cárdenas Gutiérrez, 2002, p. 199).

En los virreinatos americanos, esa dimensión representativa de la figura del rey fue potenciada. La veneración con la que fue recibido y manipulado el real sello desde el inicio del proceso de colonización muestra que existía un propósito de afianzar la autoridad de los ausentes monarcas. Este artefacto regio fue empleado como símbolo de unidad ante la fragmentación política derivada de la gran heterogeneidad constitutiva de las expediciones de conquista y asentamiento. En directa vinculación con lo anterior, la reverencia al real sello buscaba contribuir a la pacificación de “...un espacio indómito y violento, poniendo coto a las ínfulas de poder y grandeza de capitanes y encomenderos" (García Bernal, 2014, pp. 190-191).

En una audiencia pretoriana ${ }^{2}$, como la guatemal-

2 Ruiz Guiñazú, en La magistratura indiana (1916) citado por Ortiz Treviño (1998, p. 678), distinguió entre audiencias virreinales, subordinadas y pretoriales o pretorianas. Las virreinales son presididas por el virrey; las subordinadas carecen de potestades de gobierno y dependen del virreinato más cercano; y las pretoriales son aquellas en las que el presidente goza de facultades de gobierno. El término "audiencia pretoriana", sin embargo, procede de la obra de Antonio de León Pinelo, autor de la magna Recopilación de las leyes de los reinos de la Indias, encargada por Felipe IV. En 
teca, se prescindía de la poderosa presencia física y simbólica - alter ego del monarca- del virrey. Los vínculos de dependencia política y administrativa se establecían directamente con las instituciones peninsulares. La máxima figura en la jerarquía política era la del capitán general y presidente de la audiencia, la cual, a pesar de recibir los honores de su cargo, distaba mucho de competir con la preminencia debida a los virreyes. Esa especie de vacío era subsanado, en alguna medida, por el respeto dispensado a los símbolos del poder real: el pendón, presente ante todo en la ceremonia de proclamación, pero también en otros cortejos, y el sello, cuyo uso ceremonial era excepcional al estar limitado al festejo de su recibimiento. ${ }^{3}$

En el reino de Guatemala tan solo se publicó una relación sobre los festejos de recibimiento del real sello: la Breve relación de la solemnidad y augusta pompa con que se recibio en la Capital del Reyno de Guatemala el Real sello de nuestro reinante Catolico Monarca el Señor Carlos IV. La consagra a la reyna nuestra señora doña Maria Luisa de Borbon el chanciller de la Real audiencia del mismo reyno $d$. Juan Miguel Rubio, y Gemmir quien la da a luz y de cuyo encargo la compuso el m.r.p. mtro. Provincial fr. Carlos Cadena (1793). ${ }^{4}$ Su autor, el dominico Carlos Cadena, era una figura intelectual consagrada y reconocida como escritor de relaciones festivas. A su ha-

su Libro II, Título XV, Ley VI, se fijan los límites territoriales y las potestades de la Audiencia y Chancillería Real de Santiago de Guatemala. Allí se establece "que el Governador y Capitan General de las dichas Provincias, y Presidente de la Real Audiencia de ellas, tenga, use y exerza por si solo la gobernación de aquella tierra, y de todo su distrito, assi como la tiene nuestro Virrey de la Nueva España..." (1774, p. 189). El mismo León Pinelo, en el Tratado de confirmaciones reales, de encomiendas, oficios y casos, en que se requieren para las Indias Occidentales (1630), incluye la audiencia de Guatemala dentro de las pretoriales, cuando señala: “...las Audiencias Pretoriales, que no reconocen en las Indias a Virrey ninguno, i estas son seis. La del Nuevo Reyno de Granada en el Perû: la de Panamà, en Tierrafirme: la de Guatimala, en Nueva España: la de Guadalaxara, en la Galicia: la de Manila, en las Islas Filipinas: i la de Santo Domingo, en la Española" (1630, p. 136). Esta condición se traducía, en la práctica, en la independencia de la audiencia de Guatemala, como unidad política y administrativa, respecto del virreinato de Nueva España y solo subordinada al Consejo de Indias.

3 Antonio Batres Jáuregui, en el segundo volumen de La América Central ante la historia (1920, p. 118), presenta una curiosa imagen, mezcla de realidad y fantasía, del real sello.

4 La Biblioteca Nacional de Chile cuenta con un ejemplar en la Sala Medina, FHA 182.7. En la Biblioteca Pública de Nueva York hay dos ejemplares (KE 1793) y otro en la Biblioteca de la Universidad de Tulane, Latin American Library (Rare Books) 972.81 (929.8) C122b. Mencionada por Palau y Dulcet (1950, p. 25), Medina (1964, p. 274) y Díaz Vasconcelos (1942, p. 169). ber contaba con la publicación de dos notables textos, El triumpho contra la muerte De la Real, y Generosa Aguila de España. Sentimientos tristes, que en las fúnebres exequias a la memoria de Nuestra Catholica Reyna, y Heroina Dña. Isabel Farnesio Manifestó La muy Noble Ciudad de San Salvador en el Reyno de Guathemala (1767) y la Descripción de las Reales exequias que a la tierna memoria de nuestro Augusto, y católico Monarca el Señor D. Carlos III... se hicieron de orden del Real Acuerdo en la Muy Noble y Leal Ciudad de Guatemala (1789).

La especial vinculación del recibimiento del real sello con el advenimiento de un nuevo monarca posibilitó un curioso fenómeno que no se repite en los restantes tipos de relaciones festivas de la audiencia de Guatemala. ${ }^{5}$ En dos de las relaciones dedicadas a celebrar la continuidad dinástica - las proclamaciones de Fernando VI (1747) y Carlos III (1761) en Santiago de Guatemala - se encuentran amplios segmentos consagrados a narrar el recibimiento del real sello. ${ }^{6}$ Esta particularidad de combinar en un solo texto dos tipos diversos de relaciones festivas - la proclamación y la recepción del real sello - no era la norma. ${ }^{7}$

Es bien sabido que las recepciones del real sello no motivaron una gran profusión de relaciones a lo largo del continente. La práctica usual en la América virreinal era que solo el recibimiento del primer sello de un reinado promoviera grandes festejos, en tanto que el arribo de los siguientes habría merecido una atención y un festejo mucho más moderados. Las limitaciones económicas y el escaso desarrollo de la tradición relacionera guatemalteca, posiblemente, habrían propiciado la inclusión, dentro de los relatos de

5 Para una completa tipología de las relaciones de fiestas del reino de Guatemala, véase Sánchez Mora (2016, pp. 136-146).

6 Se trata de la Relacion historica de las reales fiestas que la Muy Noble, y muy leal Ciudad de Santiago de los Caballeros de Guatemala, celebró desde el dia 8 de abril de 1747 años en la proclamacion de Ntro. Catholico Monarca, el Sr. D. Fernando VI (1747) de Francisco López Portillo y de la Relacion de las Fiestas Reales que la Noble y Fidelissima Ciudad de los Caballeros de Santiago de Guatemala, hizo en la jura del Rey nuestro señor D. Carlos III (1761) de Manuel de Batres.

7 Un caso de interés en el contexto centroamericano se produce con el deceso de Carlos III y el advenimiento de Carlos IV. En la ciudad de Granada, provincia de Nicaragua, Las ceremonias de exequias fúnebres y de subsecuente proclamación fueron celebradas con la publicación de un libro doble, obra de Pedro Ximena: Reales exequias por el Sr. D. Carlos III, rey de las Españas, y Américas. Y real proclamación de su augusto hijo el señor D. Carlos $I V$, por la muy noble, y muy leal ciudad de Granada, provincia de Nicaragua, reino de Guatemala (1793). 


\section{Figura 1}

Portada de la Breve relación de la solemnidad y augusta pompa con que se recibió en la capital del reino de Guatemala el real sello de nuestro reinante católico monarca el señor Carlos IV...

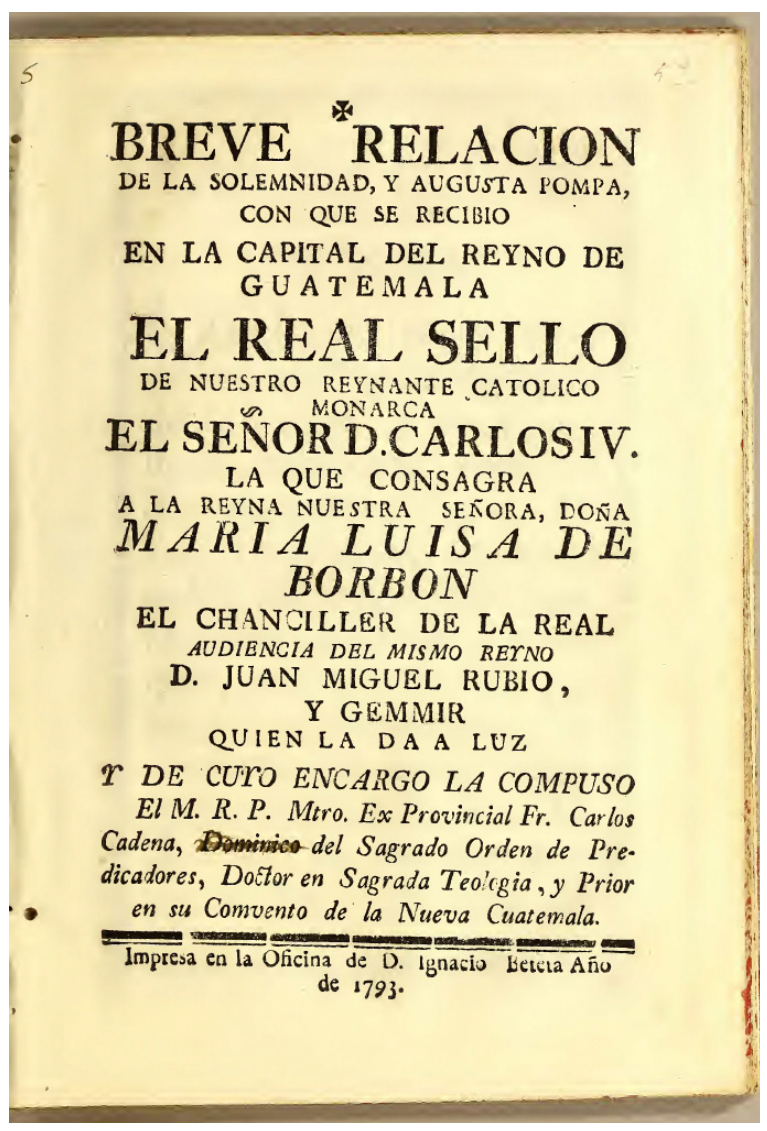

Nota. De "Breve relación de la solemnidad y augusta pompa con que se recibió en la capital del reino de Guatemala el real sello de nuestro reinante católico monarca el señor Carlos IV..." por Carlos Cadena, 1793. https://archive.org/ details/breverelaciondel00cade/page/54/mode/2up

proclamación, de la fiesta del sello real: como prólogo en la fiesta de Fernando VI o como epílogo en la de Carlos III.

Estas circunstancias demuestran que la publicación individual de la Breve relación de la solemnidad $y$ augusta pompa con que se recibió en la capital del reino de Guatemala el real sello de nuestro reinante católico monarca el señor Carlos IV... (1793) de Carlos Cadena, único festejo de esta naturaleza que mereció la distinción de una edición individual, fue un acontecimiento notable. De tales prácticas de escritura y edición se infiere que la inclusión o no de la fiesta del real sello dentro del libro de proclamación dependió de aspectos por entero prácticos. En los dos casos conocidos, las proclamaciones-recepción de real sello de Fernando VI y Carlos III, esta convergencia tipológica fue posible debido a que el real sello arribó a la ciudad de Guatemala dentro de un plazo anterior o posterior muy cercano a la fecha de la proclamación real. En la relación de Carlos Cadena, por el contrario, median tres años entre la jura de Carlos IV y la llegada de su sello, distancia temporal que atentó contra su fusión con el relato de la proclamación.

Además de estas relaciones impresas, existe al menos una relación manuscrita de recibimiento de real sello en el reino de Guatemala: Relacion de las operaciones del Excelentisimo Ayuntamiento de esta Muy Noble y Muy Leal Ciudad de Guatemala para el recibimiento publico del Real Sello de su Majestad reinante el Señor Don Fernando $7^{\circ}$ que Dios guarde, con arreglo a los pasajes de actas (Archivo General de Centroamérica [AGCA], Signatura 15744, Legajo 2193, Folios 17-19, 1818).

Se trata, como salta a la vista, de una expresión bastante tardía de este tipo específico de relación, lo cual resulta de sumo interés por cuanto permite constatar la persistencia o la variación de las prácticas y la retórica festiva en los años finales de la presencia política española en Centroamérica.

\section{La estructura retórica de la Breve relación... de Carlos Cadena}

La Breve relación de la solemnidad y augusta pompa... sobre el recibimiento del real sello de Carlos IV, escrita por el dominico Carlos Cadena, es la más completa muestra de este ceremonial en el reino de Guatemala. Por esta razón, nos concentraremos en el estudio de su conformación retórica y recurriremos a las tres restantes -las dos insertas en relaciones de proclamación y la manuscrita- para verificar o, si fuera el caso, contrastar lo expresado en ella.

Ledda (1996 pp. 227-238) ha realizado un aporte fundamental a la configuración de una tipología de la escritura de la fiesta a partir de consideraciones retóricas. Su tipología de las relaciones extensas de fiestas religiosas barrocas toma en cuenta tres aspectos: (1) la selección, inclusión y exclusión de materiales, (2) la dispositio o distribución de los materiales y (3) la enunciación o presentación en el plano del discurso. En términos clásicos, esta categorización se basa en 
las fases de elaboración del discurso: inventio, dispositio y elocutio.

En este artículo nos concentraremos en la dispositio u organización estructural de la relación de Carlos Cadena. La consideración de cada una de sus partes permitirá una visión de conjunto de las estrategias de organización del discurso relatorio. La relación se ordena en cuatro grandes secciones. La primera no es parte propiamente dicha de la relación, pues es un cuerpo de siete paratextos que, a manera de introducción, guían al lector y cimientan la legitimidad de la relación festiva. La relación en cuanto tal consta de tres partes. La primera es un exordio que da las pautas generales de descodificación del texto y que enlaza la retórica de la exaltación dinástica con las reivindicaciones criollas. La segunda contiene una pormenorizada descripción de la ornamentación -colgaduras, escudos, estatuas y poesías- que engalanó los sitios ceremoniales. La tercera es el relato de la ceremonia de recepción y juramento del real sello y finaliza con la fundición del anterior sello. ${ }^{8}$

\section{Los paratextos de la Breve relación... de Carlos Cadena}

La noción de paratexto, formulada por Genette durante la década de $1980,{ }^{9}$ remite al conjunto de producciones discursivas que acompañan al texto y que, a manera de umbral, establecen su relación con el lector (Genette, 1987, p. 73). El paratexto, en general, corresponde a segmentos que ocupan una posición estratégica que les permite introducir, orientar y asimilar el texto literario (Amoretti, 1992, p. 87). Estas instancias de introducción del texto se ofrecen como marcas que orientan el trabajo de descodificación del lector, que intentan conducirlo de conformidad con el proyecto autorial. Los paratextos, en consecuencia, proponen un contrato de lectura que instala un sentido previo, una presuposición (Amoretti, 1989, p. 67).

El aparato paratextual, o preliminares, de la relación de Cadena está compuesto por el usual dispositivo institucional de aprobaciones y licencias que daban cuenta de la ortodoxia doctrinal de los manuscritos como paso previo a su publicación. La relevancia de esta sección liminar trasciende ese propósito de legiti-

8 Esta división tripartita de la relación es una propuesta de García Bernal (2014, p. 209).

9 Lo esboza primero en su libro Palimpsestes (1981) y lo desarrolla con amplitud en Seuils (1987). mación de la palabra, pues los autores de tales textos no se limitaban a constatar el apego al dogma católico y las buenas costumbres, sino que aprovechaban a oportunidad para manifestar sus propias opiniones sobre múltiples temas vinculados con el despliegue del fasto. Los paratextos de la relación de fray Carlos Cadena no son la excepción. Se trata de siete textos que abarcan veinticuatro páginas sobre el total de sesenta y dos que tiene la relación, lo que demuestra su significativo peso. El primero es la dedicatoria del chanciller Juan Miguel Rubio y Gemmir a la reina María Luisa de Borbón. Le siguen el dictamen de Juan José González de Batres, deán de la catedral; la licencia del presidente de la audiencia, Bernardo Troncoso Martínez del Rincón; la aprobación de fray José Antonio Goicoechea; la licencia del deán y cabildo sede vacante de la catedral; la aprobación del dominico fray Fermín Aleas y, finalmente, la licencia de la orden de predicadores.

En varios de los componentes de este umbral paratextual la idea que predomina es la de explicitar el fundamento del festejo y, por extensión, de la relación misma. Desde la dedicatoria, el chanciller Rubio y Gemmir, encargado de la organización del programa celebratorio, es claro al exponer que sus acciones son guiadas por sentimientos de lealtad, amor y veneración hacia la monarquía (Cadena, 1793, pp. 3-4). El franciscano Goicoechea confirma tales asertos cuando sostiene que la relación describe "con mano diestra la lealtad, subordinación y rendimiento con que todos los cuerpos de este reino se esforzaron a rendir obsequios debidos a nuestros soberanos" (Cadena, 1793, p. 15).

Las declaraciones de amor, obligación y lealtad son proclamas convencionales que atraviesan los diferentes tipos de relatos festivos, ya sean de honras fúnebres, proclamaciones, recibimientos o cumpleaños, entre otros. Sin embargo, en pocas ocasiones se encuentra una manifestación tan completa sobre la utilidad de eternizar la relación "por medio de los moldes" como la que propone el deán González de Batres:

Será un monumento del amor, celo y esmero con que V. E. y los señores ministros de esta real audiencia han dado el lleno a la ley en que el rey quiere que su real sello se reciba con la misma autoridad que a su real persona. Será un documento que acreditará en todo tiempo los timbres de muy noble y leal de que goza esta ciudad, a que ya pudiera añadirse el de muy magnífica, por la gran magnificencia con que se ha portado en esta ocasión. En fin, será un testimonio de la generosa liberalidad del chanciller, que estimulará a sus sucesores a seguir sus huellas (Cadena, 1793, p. 11). 
González de Batres señala tres funciones primordiales para la versión literaria del fasto. En ellas se condensan las funciones del discurso relatorio del efímero barroco: la transmisión de un sistema de control ideológico, la promoción personal, la formulación de un discurso identitario y de una propuesta utópica.

Aunque González de Batres no afirme en forma explícita que la relación debe defender y difundir el sistema axiológico vinculado con la monarquía borbónica, este es su presupuesto de partida. La lealtad al rey es el axioma que todo lo impregna, el principio que debe guiar la conducta de los funcionarios reales y de la ciudad como un todo. La promoción personal es clara en el postulado de que la munificencia de $\mathrm{Ru}$ bio y Gemmir al costear los gastos de los júbilos es un modelo digno de imitación. El discurso identitario aparece en la exaltación de la ciudad, de su gloria por el título de muy noble y muy leal ciudad otorgado, por el emperador Carlos V en 1566, a Santiago de los Caballeros de Guatemala (Fuentes y Guzmán, 1969, p. 202).

En este sentido, García Bernal señala que el deán considera la relación como monumento, "testigo de una acción colectiva que adquiere, por medio de la elaboración narrativa, estatuto perdurable", y como documento, "materialidad impresa que acredita como si se tratase de una probanza de hidalguía, la nobleza colectiva de los ciudadanos de Nueva Guatemala" (2014, p. 207). ${ }^{10}$ Por último, la propuesta utópica se hace presente en la adjudicación del título de muy magnífica a una urbe que, según el escritor, no se ha contenido en el gasto ni en la demostración de júbilo. La grandiosidad, la magnificencia del festejo barroco crea un mundo alternativo, una ciudad ideal que rompe con los límites e imperfecciones de la ciudad material.

\section{Exordio: entre la fidelidad monárquica y la reivindicación criolla}

El exordio se abre con una media portadilla que dice "Ingreso y recibimiento que se hizo en la capital del reino de Guatemala del real sello de nuestro católico reinante soberano el señor don Carlos IV" (Cadena, 1793, p. 25). Desde el incipit, con su decisivo poder como programador de lectura, se define un trayecto

10 Ambos significados, como monumento y como documento, se dirigen a una memoria de la ciudad que está por hacerse, pues en esos momentos estaba reciente el traslado de la capital a su nuevo asiento en el 1760 de La Ermita, de modo que "el acto efímero del recibimiento del Real Sello sería un primer y esperanzador jalón" (García Bernal, 2014, p. 207).

\section{Figura 2}

Portada de la casa del Chanciller

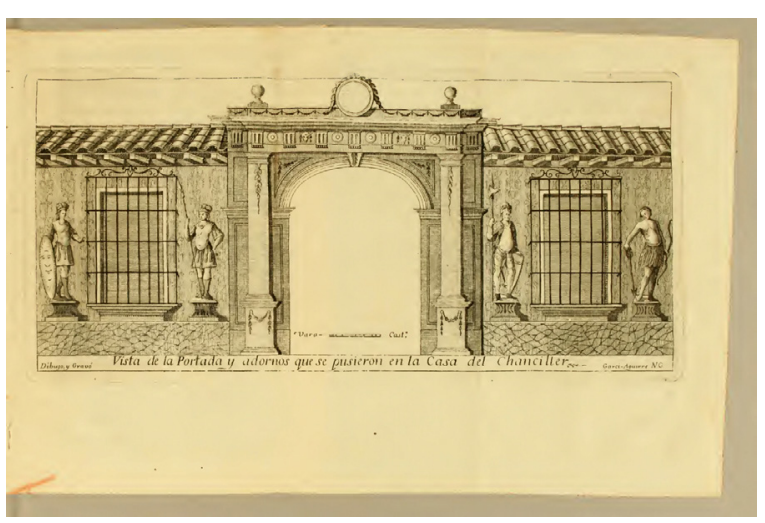

Nota. De "Breve relación de la solemnidad y augusta pompa con que se recibió en la capital del reino de Guatemala el real sello de nuestro reinante católico monarca el señor Carlos IV...” por Carlos Cadena, 1793. https://archive.org/ details/breverelaciondel00cade/page/54/mode/2up

de significación que acerca esta relación a las de proclamación y jura. En efecto, en los párrafos iniciales se recurre a la misma estrategia retórica empleada en los relatos de las fiestas de la continuidad dinástica: la oposición binaria dolor / alegría. ${ }^{11}$

Y cuando al reino absorbía el mayor dolor, se mira dulcemente arrebatado de alegría, sabiendo que el trono del gran CARLOS III se ocupa y llena, con toda propiedad, por su augusto hijo y sucesor heredero de su corona y de su grande alma, el señor D. Carlos IV, que Dios guarde (Cadena, 1793, p. 26).

Esta antinomia se encuentra planteada en forma fundacional en la Relacion histórica de las reales fiestas... (López Portillo, 1747) de Fernando VI bajo la contraposición de Volupia, diosa de la sensualidad, y Angerona, diosa de la angustia y el miedo. A lo largo de todo el siglo XVIII, tal dualidad sería repetida en la Relacion de las fiestas reales... (1761) por la proclamación de Carlos III de Manuel Batres, en la Relación de las fiestas... en la proclamación del Sr. D. Carlos IV (1790) de Mariano López Rayón y en la Real proclamacion por el Señor D. Carlos IV... (1793) en Granada, Nicaragua, de Pedro Ximena.

En el texto de Cadena, el recurso al recuerdo del dolor por el deceso de Carlos III cumple la función de potenciar el alborozo por el advenimiento al tro-

11 Sobre las relaciones de fiestas de proclamación real en el reino de Guatemala, Sánchez Mora (2017, 2018a y 2018b). 
no de Carlos IV y, sobre todo, de extender esa dicha al arribo, más de dos años después, de su real sello. ${ }^{12}$ El deslumbrante efímero que la relación propone actúa como feliz augurio para una población en trance de lenta recuperación tras la refundación de la ciudad (García Bernal, 2014, p. 207). ${ }^{13}$ La recreación literaria del fasto no deja traslucir bajo ninguna circunstancia la realidad de una ciudad aquejada por multitud de problemas derivados de su masivo traslado y que tardarían décadas en alcanzar algún tipo de solución. Por el contrario, la exultante retórica pinta una ciudad de maravilla en la que los desfiles, las colgaduras, las iluminaciones, la música, las salvas de artillería y las campanadas aturden y alegran los sentidos.

El júbilo por la entronización de Carlos IV se manifiesta mediante un panegírico que remite al estilo ilustrado que ya había hecho aparición en el reino de Guatemala en el relato de las honras fúnebres de Matías Gálvez (1785) escritas por fray Francisco Antonio de Goicoechea y en las de Carlos III (1789) del propio Carlos Cadena. Se trata de una alabanza que se distancia de los modelos barrocos, pletóricos de referencias mitológicas y bíblicas, y que fundamenta su elogio en la mención de las obras concretas del personaje en cuestión.

En el fasto de recibimiento del real sello se construye una imagen del nuevo soberano como gran benefactor de las Américas a partir de una realización específica: la fundación del Colegio de Nobles Americanos en Granada. El propósito de esta institución sería "dar a los jóvenes naturales de los dominios del rey en las Indias Occidentales e islas Filipinas una educación civil y literaria que los habilite a servir en la iglesia, la magistratura, la milicia y los empleos públicos" $(\mathrm{Ca}-$ dena, 1793, pp. 28-29). La transcripción de una parte de la real cédula de creación del colegio enfatiza el talante ilustrado del elogio, pues, como sucedió en las exequias de Gálvez y de Carlos III, era práctica normal la inclusión de textos de orden jurídico en sustitución de las tradicionales referencias clásicas y teológicas.

La elección de esta obra regia como eje del panegírico no es casual, pues responde a la perfección a los intereses de los criollos, quienes se verían benefi-

12 Los festejos por la proclamación de Carlos IV se efectuaron del 17 al 26 de noviembre de 1789 y su real sello solo llegaría el 13 de mayo de 1792 (Cadena, 1793, pp. 32-33).

13 Sobre el traslado de la capital pueden consultarse los trabajos de T.Sagastume Paiz (2008), Peláez Almengor y colaboradores (2007), C. Pinto Soria (1994), Langenberg (1989) y Zilbermann Morales (1987). ciados por la posibilidad de ocupar puestos dirigentes hasta entonces reservados a los peninsulares. Cadena es directo cuando sostiene que este colegio permitiría detener la migración de españoles a América, lo cual denuncia el malestar criollo ante el aumento de la presencia española en el continente durante el siglo XVIII (Pérez, 1977, p. 13). ${ }^{14}$ En este sentido, la relación de Cadena, como apunta García Bernal, se mueve entre la continuidad y el cambio: de la primera porque propicia la subsistencia de la tradición y del segundo en el tanto introduce "los nuevos valores del absolutismo ilustrado en un esfuerzo postrero por apuntalar los principios de un sistema que en muchos lugares empezaba a ser cuestionado" (2014, p. 202). Así, la relación hace gala de una adhesión en apariencia incuestionable al régimen borbónico y sus símbolos, pero no basa esa lealtad en genéricos sentimientos de amor y obligación, sino en unas ansias reformistas que habrían otorgado mayor autonomía e iniciativa política a las élites criollas.

El enlace con la tradición ritual encuentra su punto álgido en la enorme importancia que se confiere a los textos jurídicos. La primera referencia a ellos se da cuando se explica que el recibimiento del real sello no se celebró en conjunción con la proclamación del monarca porque esta se efectuó en noviembre de 1789 en tanto que aquel arribó apenas con el correo del 13 de mayo de 1792, el cual portaba también la real cédula que mandaba disponer los homenajes de ley. De inmediato, se transcribe la cédula en su integridad (Cadena, 1793, pp. 32-33).

A partir de este punto se hace énfasis en que todas las disposiciones que se han de tomar para organizar el recibimiento del real sello, iniciando por el nombramiento de comisionados que velen por el cumplimiento estricto del ceremonial, responden a un mandato taxativo de la ley. Inclusive, se capta a la perfección

14 En su estudio sobre venalidad y méritos en la provisión de cargos americanos durante la primera mitad del siglo XVIII, Guillermo Burgos Lejonagoitia (2014, p. 397) demuestra que este fenómeno venía de mucho tiempo atrás, pues ya durante los reinados de Carlos II y Felipe V la presencia de peninsulares había sido mayoritaria en la provisión de cargos de todas las categorías (políticos, político-militares, hacienda y justicia). Las reformas borbónicas, sin embargo, ahondaron la tendencia y promovieron el desplazamiento a América de numerosos contingentes de administradores españoles. Además, el crecimiento demográfico que experimentó la península durante el siglo XVIII estimuló la migración hacia las posesiones de ultramar en búsqueda de mayores posibilidades económicas. Al decir de Pérez, "como consecuencia de todo ello, que se hace sensible sobre todo a finales de la centuria, los españoles siguen siendo minoritarios, pero su peso político y económico es mucho mayor y llama más la atención" (1977, p. 13). 
la gradación jerárquica de las fuentes del Derecho que posibilitan el ritual celebratorio: las Leyes de Indias son el marco jurídico general que estipula el deber celebratorio, la real cédula es la ejecución de tal disposición legislativa y, finalmente, un bando administrativo del presidente Bernardo Troncoso es el cuerpo de medidas concretas para que el festejo ocurra con la debida pompa y orden (iluminación general de la ciudad, colgaduras en las calles, prohibición de parada de coches y paso de caballos a lo largo del recorrido del desfile) (Cadena, 1793, p. 36).

En las relaciones de recibimiento del real sello el cumplimiento de la ley ocupa un sitial de honor, posiblemente más destacado inclusive que en las relaciones de proclamación. En estas últimas el respeto al ceremonial es de gran importancia, pero admiten ciertas variaciones dentro de la línea maestra; por ejemplo, la proclamación puede verificarse en uno o dos tablados, las fórmulas de proclamación enunciadas por el alférez real - aunque dentro de un mismo esquema básico - presentan diferencias, la missilia munera o lanzamiento de monedas puede verificarse o no, etc. Por el contrario, la observancia del protocolo dictado por las normas jurídicas - la Ley I, Título 21, Libro 2 de la Recopilacion de Leyes de los Reynos de las Indias - es casi siempre muy estricto en las relaciones dedicadas al real sello, ya se trate de los relatos insertos en las relaciones de proclamación de Fernando VI y Carlos III, en la relación impresa de Carlos Cadena o en la manuscrita sobre el real sello de Fernando VII. ${ }^{15}$

Las celebraciones de la lealtad, en forma general, estuvieron marcadas por un lenguaje simbólico ligado a una obligación impuesta por un mandato normativo (Cárdenas Gutiérrez, 2002, p. 200). Tratándose del real sello, el cumplimiento de ese acto jurídico adquiere un relieve inusitado y explica las constantes declaraciones de que lo realizado responde a los designios

15 Dicha ley establece: "Es justo y, conveniente, que quando nuestro sello Real entrare en alguna de nuestras Reales Audiencias, sea recibido con la autoridad, que si entrasse nuestra Real persona, como se hace en las de estos Reynos de Castilla: Por tanto mandamos que llegando nuestro sello Real à qualquiera de las Audiencias de las Indias, nuestros Presidentes y Oidores, y la Justicia y Regimiento de la Ciudad salgan un buen trecho fuera de ella a recibirle, y desde donde estuviere, hasta el Pueblo sea llevado encima de un cavallo, ò mula, con aderezos muy decentes, y el Presidente, y Oidor mas antiguo le lleven en medio, con toda la veneracion que se requiere, segun y como se acostumbra en las Audiencias Reales de estos Reynos de Castilla, y por esta orden vayan hasta ponerle en la Casa de la Audiencia Real, donde estè, para que en ella le tenga a cargo la persona que sirviere el oficio de Chanciller del sello, y de sellar las provisiones, que en las Chancillerìas se despacharen" (León Pinelo, 1774, pp. 243). legales, al estilo de la siguiente dedicada a la real insignia de Fernando VI:

Así se concluyó este acto por lo que mira a su ceremonial tan arreglado a las leyes, que manda su majestad observar en las entradas de sus reales sellos, ejecutándose estas con la misma autoridad que si fuese su real persona (López Portillo, 1747 p. 11). ${ }^{16}$

Ese apego enfático a la normativa responde a la naturaleza dual del objeto símbolo que motiva el fasto. El real sello es encarnación simbólica de la figura del monarca. ${ }^{17}$ Esta capacidad de representar al rey, compartida con los retratos, el real estandarte y, en menor medida, las medallas de proclamación, justifica los repetidos testimonios de que debía recibir el mismo trato que se dispensaría a la regia persona. El sello, en palabras del franciscano Goicoechea, es "una de las insignias más características de la soberanía" (Cadena, 1793, p. 15).

Este aspecto conduce a la siguiente manifestación de la apuntada naturaleza dual del sello: condensa el poder judicial asociado al monarca. Es símbolo de la recta y superior justicia del soberano, de su condición de garante de la convivencia armoniosa entre sus súbditos. Sin embargo, al mismo tiempo, supera ese carácter representativo y desempeña una función material en la administración judicial, pues funge como instrumento de validación de los documentos expedidos por los tribunales en el ejercicio de su función jurisdiccional. Símbolo del rey y herramienta al servicio de la actividad cotidiana de la real audiencia, esa sería la condición bifronte del real sello. Por lo tanto, el exaltado respeto del ritual establecido por la ley que se percibe en las relaciones de su recibimiento sería un resultado de su participación clave en el mundo forense.

16 En la relación de Cadena, entre otros muchos ejemplos, se dice: "Debiendo entrar el real sello en un caballo o mula con aderezos muy decentes conforme a la citada ley [...]" (1793, p. 56). Como señala García Bernal, "no transcurren dos páginas sin que el autor recuerde que los homenajes se hacían 'según la ley citada' " (2014, p. 211). En la relación de recibimiento del real sello de Fernando VII en 1817 se menciona únicamente que los actos se organizan "según el ceremonial aprobado por su majestad" (AGCA, Signatura15744, Legajo 2193, Folio 17, 1818). Esta última relación no fue pensada para su publicación, sino como una constancia de lo actuado por el cabildo y como tal se adjuntó a su libro de actas. Este carácter notarial explica la simplificación de algunas fórmulas de la escritura del ritual.

17 Sobre la trascendencia del sello, cita Cárdenas Gutiérrez: "En Castilla, según Percy Schramm, el sello real cobró tal importancia que desplazó a la corona o a la diadema, como el máximo símbolo de la realeza" (2002, pp. 198-199). 


\section{La arquitectura efímera: descripción del castillejo}

La segunda parte de la relación de Cadena comprende la descripción de una arquitectura efímera -un castillejo- en el palacio de la audiencia, la decoración de su fachada y de las puertas frente a ella, de un tablado en la iglesia del Calvario y de la ornamentación de la casa del chanciller Juan Miguel Rubio y Gemmir, encargado de recibir y custodiar el real sello (Cadena, 1793, pp. 37-49). El programa iconográfico que allí se despliega ha sido estudiado con amplitud y detalle por García Bernal (2014, pp. 212-218), por lo que aquí solo nos interesarán los motivos fundamentales.

En las estancias del palacio y en su fachada destacan dos hilos simbólicos: el de la justicia y el de la realeza. El primero está representado por una estatua de la Justicia Vindicativa y otra de la Justicia Distributiva, cada una acompañada por una cuarteta explicativa sobre sus sendas cualidades de punición y adjudicación por méritos. El segundo combina las armas reales, un retrato ecuestre de Carlos IV sobre dos orbes y el lema del Non Plus Ultra, más estatuas de Europa, América, Asia y África (Cadena, 1793, pp. 39-42). Las efigies de la justicia remiten al real sello como condensación del poder judicial que emana de la soberanía regia. La figura del rey muestra el efectivo dominio borbónico sobre ambas orillas del Atlántico y sus posesiones en todo el mundo. Esta combinación de representaciones puede ser interpretada en forma global de la siguiente forma:

La fortaleza del Imperio que ligaba dos hemisferios, visible en las portadas del Palacio, se fundaba en el ejercicio de una justicia tan recta y expeditiva en sus sentencias como ecuánime, y liberal en la distribución de los honores. Una justicia segura e infalible, defendida por baluartes militares y rodeada de una galería de figuras alegóricas que encarnaban las virtudes y beneficios que auspiciaba el reinado de Carlos el clemente (García Bernal, 2014, p. 215).

\section{De la fiesta vivida a la fiesta contada}

Se debe a Álvarez Santaló (2001) la distinción entre las nociones de "fiesta vivida", que es la que tiene lugar en la materialidad, y "fiesta contada" o relato literario de esos hechos. La écfrasis de la fiesta -la fiesta contada- pretendía reconstruir de manera realista, aunque mejorada, esa intensa experiencia en la que la música de bandas y coros, el estruendo de

\section{Figura 3}

Portada de la casa del Chanciller

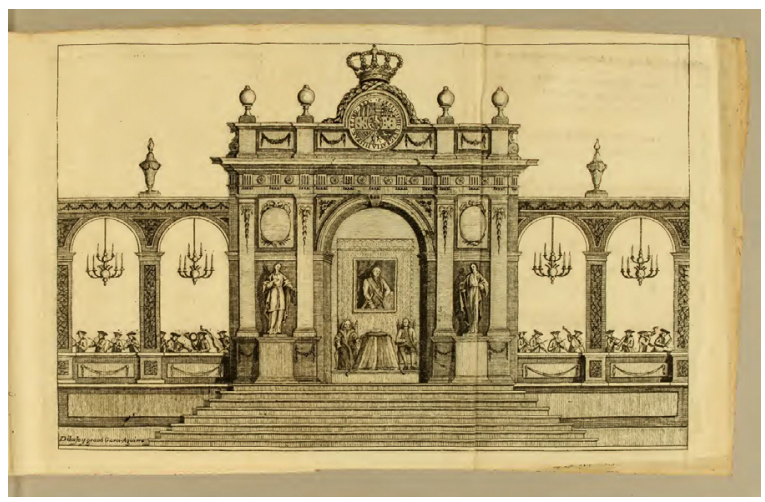

Nota. De "Breve relación de la solemnidad y augusta pompa con que se recibió en la capital del reino de Guatemala el real sello de nuestro reinante católico monarca el señor Carlos IV ...” por Carlos Cadena, 1793. https://archive.org/ details/breverelaciondel00cade/page/54/mode/2up

las campanadas y las descargas de fusilería, el disfrute táctil del terciopelo y las sedas que adornaban estrados y altares, el aroma del incienso en los actos litúrgicos y de las viandas en los convites, estimulaban todos los sentidos.

La tercera parte de la relación de Cadena corresponde a esa reconstrucción, o écfrasis, de los dos días de ceremonia. Durante la tarde del primer día se efectúa el traslado del sello desde la casa del chanciller hasta la sala donde será resguardado. El desfile, en coche, se produce en medio del júbilo popular que rinde homenaje a la insignia real, debidamente dispuesta sobre "un cojín de preciosa tela de oro y plata, matizada de colores" (Cadena, 1793, p. 51). Participaron en el tributo los indígenas de los pueblos vecinos con sus pendones, máscaras e instrumentos musicales, así como el regimiento provincial de dragones que le rindió los mismos honores debidos al rey en persona. ${ }^{18}$ El real sello fue colocado bajo dosel y custodiado por las autoridades hasta las seis de la tarde. La fiesta se completó con salvas de artillería, música de orquestas y la iluminación de las calles y de las dependencias de la audiencia y el ayuntamiento.

18 Las procesiones ocupan un lugar preminente en el ceremonial barroca: crean a ilusión de una comunidad ideal, jerarquizada, pero armónica, encabezada por un rey que se hace presente gracias a símbolos como el real sello, el estandarte real, su retrato bajo dosel o la lectura en voz alta de las reales cédulas (Puente Brunke, 2014, pp. 237-238). 
Al día siguiente, los regidores del cabildo se dirigieron al palacio para hacerse acompañar del presidente y miembros de la audiencia. A ellos se unieron las compañías de Almolonga, vistosamente trajeadas y portando arcos adornados con monedas y plumas multicolores. ${ }^{19}$ Se describen en extenso el caballo y los ostentosos jaeces que el ayuntamiento, según lo estipulado por la ley, había preparado para portar el real sello. También se presta especial atención al relato de los papeles desempeñados por cada uno de los miembros de la comitiva, siempre en concordancia con los cargos que desempeñan en la administración del reino: se indica quiénes son los encargados de tomar las riendas del caballo, fungir de paje y de sostener las varas del palio. Asimismo, se indica con precisión el orden del desfile: es abierto por los indígenas de treinta pueblos con sus pendones y las compañías de Ciudad Vieja o Almolonga; continúa el acompañamiento de la real audiencia; tras él, bajo palio, va el real sello y, a su lado, el presidente y el regente; y lo cierra la compañía de dragones provinciales (Cadena, 1793, pp. 57-58).

La entrada en el palacio se produce en medio de salvas de artillería, música y repique de campanas; una vez dentro, el chanciller entrega el real sello al presidente, quien lo porta a la sala del real acuerdo. Allí se lee la real cédula correspondiente y cada oidor toma el sello, lo besa y lo coloca sobre su cabeza. El chanciller lleva el sello hasta el sitio en el que es resguardado en forma definitiva, la oficina de la real chancillería. La relación finaliza con la mención del "refresco" ofrecido por el chanciller esa misma noche y con una última precisión legal referida a la fundición del sello de Carlos III, cuyo peso habría sido enviado a España de conformidad con lo mandado por la real cédula (Cadena, 1793, pp. 61-62).

\section{Conclusiones}

En un balance general de los relatos guatemaltecos de recibimiento del real sello, desde el de Fernando VI de 1760 hasta el de Fernando VII en 1818, el elemento que se percibe con más fuerza es la persistencia de una tradición celebratoria que abarca, por igual, los actos ceremoniales y festivos como su versión literaria. Fuera de la relación de Carlos Cadena, la de 1760 es la más rica en detalles y la que permite comprobar cómo hay una fuerte continuidad a lo largo del siglo XVIII y hasta avanzado el XIX. La descripción minuciosa de la ornamentación de las oficinas gubernamentales, del séquito que traslada la insignia y de la ceremonia de recepción por parte de la real audiencia en 1760 coincide en lo fundamental, y hasta en lo accesorio, con lo ejecutado y relatado en 1793 por Cadena. En esta última se introducen actitudes ilustradas - como la exaltación del mérito individual por las obras o la presencia de textos y alusiones diversas de las fuentes clásicas y bíblicas - y preocupaciones de la élite criolla que preludian, aún muy tenuemente, las reivindicaciones de la época independentista. Sin embargo, el apego a la letra de la ley que ha consagrado un ritual, determinado por la naturaleza jurídica del sello, es el factor de mayor peso en estos textos y el que los homogeniza.

Semejantes reflexiones son aplicables, también, a la relación manuscrita que el ayuntamiento de la ciudad de Guatemala mandó adjuntar a su libro de actas en 1818. Su ámbito más restringido de circulación y su condición de texto de primaria función administrativa lo convierten en un texto distanciado de la retórica literaria y mucho más afín a los giros del lenguaje de pretensiones referenciales. En sus escasas cuatro cuartillas se ofrecen, por ejemplo, mayor información sobre los aspectos económicos de la celebración que en todos los libros de fiestas que celebran la lealtad. Al inicio de la relación se explica que los comisionados del fasto presentaron al ayuntamiento un presupuesto de 1535 pesos que deberían ser suficientes para cubrir los gastos del palio y los arneses para el caballo sobre el cual se trasladaría el sello y que se autorizó su giro a cuenta de los fondos de propios.

El perfecit de esta relación de 1818 lo constituye una liquidación de los gastos efectivos - 1256 pesos con cuatro reales - más la indicación de que el mantillón y el cojín fueron donados a las "Beatas Rosas" para la confección de un palio y que se entregó al portero de la real audiencia la cantidad de veinticinco pesos, como se estilaba en semejantes ocasiones (AGCA, Signatura 15744, Legajo 2193, folio 19, 1818). En las relaciones literarias solo se alaba la liberalidad en los gastos y las cifras monetarias exactas habrían desentonado con el tono hiperbólico que construye el fasto. A pesar de estas diferencias, lo más reseñables es, de nuevo, la extraordinaria persistencia de un ritual que es respetado con toda precisión.

19 En la relación se anuncia la lámina que ilustra la apariencia de las compañías de Ciudad Vieja o Almolonga (Cadena, 1793, pp. 55), pero no consta en el ejemplar que hemos podido consultar. 


\section{Referencias}

Álvarez Santaló, C. (2001). La fiesta barroca contada: Una demostración retórica consciente. En M. Peña Díaz, P. Ruiz Pérez \& J. Solana Pujalte (Coords.), La cultura del libro en la Edad Moderna. Andalucía y América (pp. 47-84). Servicio de Publicaciones de la Universidad de Córdoba.

Amoretti, M. (1989). Introducción al socio-texto: A propósito de Cachaza. Editorial de la Universidad de Costa Rica.

Amoretti M. (1992). Diccionario de términos asociados en teoría literaria. Editorial de la Universidad de Costa Rica.

Batres, M. de. (1761). Relación de las fiestas reales que la noble y fidelísima Ciudad de los Caballeros de Santiago de Guatemala, hizo en la jura del rey nuestro señor D. Carlos III. Imprenta de Sebastián de Arévalo.

Batres Jáuregui, A. (1920). La América Central ante la historia, Tomo II. Tipografía Sánchez \& De Guise.

Burgos Lejonagoitia, G. (2014). Gobernar las Indias: Venalidad y méritos en la provisión de cargos americanos, 1701-1746. Editorial de la Universidad de Almería.

Cadena, C. (1767). El triumpho contra la muerte De la Real, y Generosa Aguila de España. Sentimientos tristes, que en las fúnebres exequias a la memoria de Nuestra Catholica Reyna, y Heroína Dña. Isabel Farnesio Manifestó La muy Noble Ciudad de San Salvador en el Reyno de Guathemala. Imprenta de Sebastián de Arévalo.

Cadena, C. (1789). Descripción de las Reales exequias que a la tierna memoria de nuestro Augusto, y católico Monarca el Señor D. Carlos III... se hicieron de orden del Real Acuerdo en la Muy Noble y Leal Ciudad de Guatemala (1789). Imprenta de Ignacio Beteta.

Cadena, C. (1793). Breve relación de la solemnidad y augusta pompa con que se recibió en la capital del reino de Guatemala el real sello de nuestro reinante católico monarca el señor Carlos IV. La consagra a la reina nuestra señora doña María Luisa de Borbón el chanciller de la real audiencia del mismo reino d. Juan Miguel Rubio y Gemmir, quien la da a luz y de cuyo encargo la compuso el m.r.p. mtro. provincial fr. Carlos Cadena. Imprenta de Ignacio Beteta. https://archive.org/details/ breverelaciondel00cade/page/54/mode/2up

Cárdenas Gutiérrez, S. (2002). Las insignias del rey; disciplina y ritual público en la ciudad de México (siglos XVI-XVIII). Jahrbuch Für Geschichte Lateinamerikas, 39, 193-216.

Díaz Vasconcelos, L. A. (1942). Apuntes para una historia de la literatura guatemalteca. Épocas indígena y colonial. Tipografía Nacional.

Fuentes y Guzmán, F. A. de. (1969). Obras históricas de Don Francisco Antonio de Fuentes y Guzmán (Vol. 3). Ediciones Atlas.

García Bernal, J. J. (2006). El fasto público en la España de los Austrias. Secretariado de Publicaciones de la Universidad de Sevilla.

García Bernal, J. J. (2014). El recibimiento del Sello Real de Carlos IV en la Audiencia de Guatemala (1792): Epítome y epígono de una tradición secular. Revista de Humanidades, (22), 187-226. https://doi.org/10.5944/rdh.22.2014.14295

Genette, G. (1987). Seuils. Editions du Seuil.

Gómez Gómez, M. (2007). El sello real como imagen del monarca: el recibimiento del sello en la Audiencia y Chancillería de Filipinas en el año 1598. En M. del Val González de la Peña (Coord.), Estudios en memoria del Prof. Carlos Sáenz. Homenaje (pp. 249-260). Editorial Universidad de Alcalá.

Gómez Gómez, M. (2008). El sello y el registro de Indias. Imagen y representación. Böhlau Verlag.

Gómez Gómez, M. (2009). La ciudad como emblema: Ceremonias de recibimiento del sello real en Indias. En M. C. García Bernal \& S. Olivero Guidobono (Coords.), El municipio indiano: Relaciones interétnicas, económicas y sociales: Homenaje a Luis Navarro García (pp. 461-476). Universidad de Sevilla.

Gómez Gómez, M. (2014). La Cancillería Real en la Audiencia de Santo Domingo. Uso y posesión del sello y el registro en el siglo XVI. Revista de Humanidades, (22), 17-45. https://doi.org/10.5944/ rdh.22.2014.14289

Gómez Gómez, M. (2015). El documento y el sello regio en Indias: Su uso como estrategia de poder. Documenta \& Instrumenta, 13, 89-105. https://doi. org/10.5209/rev_DOCU.2015.v13.49741 
Gómez Gómez, M. (2021). El sello real en el gobierno de las Indias: Funciones documentales y representativas. En J. C. Galende Díaz (Coord.), De sellos y blasones: Miscelánea científica (pp. 361383). Universidad Complutense.

Langenberg, I. (1989). La estructura urbana y el cambio social en la ciudad de Guatemala a fines de la época colonial (1773-1824). En S. Webre (Ed.), La sociedad colonial: Estudios regionales y locales (pp. 221-249). Centro de Investigaciones Regionales de Mesoamérica, Plumsock Mesoamerican Studies.

Ledda, G. (1996). Contribución para una tipología de las relaciones extensas de fiestas religiosas barrocas. En H. Ettinghausen, V. Infantes de Miguel, A. Redondo \& M. C. García de Enterría (Coords.), Las relaciones de sucesos en España (1500-1750). Actas del Primer Coloquio Internacional (Alcalá de Henares, 8, 9 y 10 de junio de 1995) (pp. 227238). Servicio de Publicaciones de la Universidad de Alcalá-Publications de La Sorbonne.

León Pinelo, A. de. (1630). Tratado de confirmaciones reales, de encomiendas, oficios y casos, en que se requieren para las Indias Occidentales. Juan González.

León Pinelo, A. de. (1774). Recopilacion de leyes de los reynos de las Indias. Mandadas imprimir, y publicar por la magestad catolica del rey don Carlos II, nuestro señor (3. ${ }^{\mathrm{a}}$ ed.).Andrés Ortega.

López Portillo, F. (1747). Relación histórica de las reales fiestas que la muy noble, y muy leal Ciudad de Santiago de los Caballeros de Guatemala, celebró desde el día 8 de abril de 1747 años en la proclamación dentro. católico monarca, el Sr. D. Fernando VI, rey de España y de las Indias (que Dios guarde). Imprenta de Sebastián Arévalo. https:// bibliotecadigital.aecid.es/bibliodig/es/consulta/ registro.do? control=ES-MAAEC20141046584

Medina, J. T. (1964). La imprenta en Guatemala. $\mathrm{N}$. Israel.

Ortiz Treviño, R. G. (1998). La insubordinación de dos Audiencias insubordinadas (Un estado de la cuestión). Anuario Mexicano de Historia del Derecho, (10), 675-693.

Palau y Dulcet, A. (1950). Manual del Librero Hispano-Americano. Bibliografía General Española e
Hispano Americana desde la Invención de la Imprenta hasta nuestros dias, con el valor comercial de todos los artículos descritos (Tomo III). Librería Anticuaria de A. Palau.

Peláez Almengor, Ó. G., Sagastume Paiz, T., \& Muñoz Paz, M. del C. (2007). La ciudad ilustrada. Universidad de San Carlos de Guatemala, Centro de Estudios Urbanos y Regionales.

Pérez, J. (1977). Los movimientos precursores de la emancipación en Hispanoamérica. Editorial Alhambra.

Pinto Soria, J. C. (1994). Guatemala de La Asunción: Una semblanza histórica (1776-1944). Mesoamérica, 15(27), 69-92.

Puente Brunke, J. de la. (2014). La Real Audiencia de Lima, el sello real y la garantía de la justicia. $R e$ vista de Humanidades, (22), 227-241. https://doi. org/10.5944/rdh.22.2014.14296

Ramírez Barrios, J. A. (2020). El sello real en el Perú colonial: Poder y representación en la distancia. Editorial Universidad de Sevilla.

Sagastume Paiz, T. (2008). Trabajo urbano y tiempo libre en la ciudad de Guatemala, 1776-1840. Universidad de San Carlos de Guatemala, Centro de Estudios Urbanos y Regionales.

Sánchez Mora, A. (2015). Literatura y fiesta en las márgenes del imperio: Las relaciones de fiestas en centroamérica, S. XVII a XIX [Tesis doctoral, Universidad de Sevilla]. https:/idus.us.es/ bitstream/handle/11441/33534/Tesis\%20Alex\%c3\%a1nder\%20S\%c3\%a1nchez\%20Mora.pd$\mathrm{f}$ ? sequence $=1 \&$ is Allowed $=\mathrm{y}$

Sánchez Mora, A. (2016). Las relaciones de fiestas en el Reino de Guatemala, siglos XVII a XIX. Anales de la Academia de Geografía e Historia de Guatemala, 91, 115-146.

Sánchez Mora, A. (2017). Guatemala por Fernando Séptimo: Crisis dinástica, juegos de lealtad y afirmación del poder local en una relación de fiestas. Revista de Historia, (75), 155-182. https://doi. org/10.15359/rh.75.5

Sánchez Mora, A. (2018a). El fasto de la continuidad dinástica en el antiguo reino de Guatemala: Las proclamaciones y juras de Fernando VI a Carlos IV. Bibliographica americana. Revista Interdisciplinaria de Estudios Coloniales, 14(14), 56-71. 
Sánchez Mora, A. (2018b). Las fiestas de proclamación de Fernando VII en el reino de Guatemala: Trasformación y supervivencia de un modelo retórico. Atenea, (5179), 221-239. http://dx.doi. org/10.4067/S0718-04622018000100221

Sanz García-Muñoz, M. Á. (2014). El sello y registro real en Panamá: La Real Audiencia y Cancillería en el siglo XVI. Revista de Humanidades, (22), 47-73. https://doi.org/10.5944/rdh.22.2014.14290

Valenzuela Márquez, J. (1999). Rituales y fetiches políticos en el Chile colonial: Entre el sello de la Audiencia y el pendón del cabildo. Anuario de Estudios Americanos, 56(2), 413-440. https://doi. org/10.3989/aeamer.1999.v56.i2.271

Vincent, G. (1996). Pratiques culturelles ou formes symboliques? Hermès, La Revue, 7(20), 155-162.

Ximena, P. (1793). Reales exequias por el Sr. D. Carlos III, rey de las Españas, y Américas. Y real proclamación de su augusto hijo el señor D. Carlos $I V$, por la muy noble, y muy leal ciudad de Granada, provincia de Nicaragua, reino de Guatemala. Imprenta de Ignacio de Beteta

Zilbermann Morales, C. (1987). Aspectos socioeconómicos del traslado de la Ciudad de Guatemala (1773-1783). Academia de Geografía e Historia de Guatemala.

\section{Archivo General de Centroamérica (AGCA), Guatemala}

AGCA, Signatura 15744, Legajo 2193, Folios 17-19, Relacion de las operaciones del Excelentisimo Ayuntamiento de esta Muy Noble y Muy Leal Ciudad de Guatemala para el recibimiento publico del Real Sello de su Majestad reinante el Señor Don Fernando $7^{\circ}$ que Dios guarde, con arreglo a los pasajes de actas, 1818. 